\title{
PENSAMENTO ESPACIAL E INICIAÇÃO CARTOGRÁFICA NA CONSTRUÇÃO DO CONHECIMENTO GEOGRÁFICO
}

\author{
Paula Cristiane Strina Juliasz ${ }^{1}$
}

\begin{abstract}
Resumo: Os conceitos, as representações e habilidades espaciais são componentes do pensamento espacial. Temos como objetivo analisar as formas pelas quais o conhecimento geográfico pode ampliar o pensamento espacial. Apresentamos três aspectos fundamentais para construção de nossas pesquisas: a concepção de criança como sujeito com direito; o pensamento espacial como campo interdisciplinar e fundamental para Educação Geográfica; e a sequência didática enquanto metodologia de ensino. A pesquisa realizada tem se pautado na teoria histórico cultural e na perspectiva histórico crítica. As atividades de ensino foram desenvolvidas em turmas de Educação Infantil com crianças de 4 a 6 anos de idade e consideramos as interações das crianças por meio de falas e gestos e suas produções para subsidiar nosso diálogo com a teoria. O desenvolvimento dessa pesquisa demandou uma metodologia qualitativa na construção e análise dos dados, sendo coerente com nossos objetivos e referenciais teóricos.
\end{abstract}

Palavras-chave: Pensamento Espacial; Educação Geográfica; Cartografia Escolar.

Resumen: Los conceptos, las representaciones y las habilidades espaciales son componentes del pensamiento espacial. Tenemos como objetivo analizar las formas por las cuales el conocimiento geográfico puede ampliar el pensamiento espacial. Presentamos tres aspectos fundamentales para la construcción de nuestras investigaciones: la concepción de niño como sujeto con derecho; el pensamiento espacial como campo interdisciplinario y fundamental para la Educación Geográfica; y la secuencia didáctica como metodología de enseñanza. La investigación realizada se ha guiado en la teoría histórica cultural y en la perspectiva histórica crítica. Las actividades de enseñanza se desarrollaron en grupos de Educación Infantil con niños de 4 a 6 años de edad y consideramos las interacciones de los niños a través de las conversaciones y gestos y sus producciones para subsidiar nuestro diálogo con la teoría. El desarrollo de esta investigación demandó una metodología cualitativa en la construcción y análisis de los datos, siendo coherente con nuestros objetivos y referenciales teóricos.

Palabras claves: Pensamiento Espacial; Educación Geográfica; Cartografía Escolar.

\footnotetext{
${ }^{1}$ Docente Adjunta do Instituto de Educação de Angra dos Reis (IEAR) da Universidade Federal Fluminense (UFF). paulacsj@id.uff.br

Estudos Geográficos, Rio Claro, 17(1): 245-255, jan./jun. $2019 \quad$ (ISSN 1678-698X) http://www.periodicos.rc.biblioteca.unesp.br/index.php/estgeo
} 
Pensamento espacial...

\section{INTRODUÇÃO}

A cartografia escolar é uma área que relaciona conhecimentos da Educação, da Geografia e da Cartografia, consistindo assim em um campo que envolve metodologias de ensino e concepções sobre a construção e mudança conceitual, conteúdos geográficos e noções de comunicação cartográfica e o papel social dessa linguagem. $\mathrm{Na}$ escola, diversas disciplinas podem usar materiais cartográficos para desenvolver seus temas, porém é a Geografia a responsável por trabalhar a Cartografia enquanto conteúdo, por exemplo, os conceitos como relacionados à orientação, o conceito de escala cartográfica e elementos do mapa, além de desenvolver análise da realidade a partir de dados especializados em mapas.

A Geografia enquanto disciplina escolar está presente no currículo desde o primeiro ano do Ensino Fundamental, porém sabemos que ao longo da escolaridade formal, a representação do espaço, os princípios geográficos e noções espaciais e cartográficas podem ser mobilizadas desde a Educação Infantil, de tal modo que a criança desenvolve o pensamento espacial, tornando-o mais complexo quando relacionado aos conhecimentos escolares e sistematizados na escola.

Tomamos como problema a ausência de um suporte teórico-metodológico para o segmento da Educação Básica relacionado ao Pensamento Espacial, o que pode provocar deslocamento de conteúdos e práticas desenvolvidas nos anos iniciais do Ensino Fundamental para as crianças menores.

Neste artigo temos como objetivo discutir como o conhecimento geográfico pode ampliar o pensamento espacial desde a Educação Infantil, a partir de situações problemas e sequências didáticas. Portanto, tomamos três aspectos fundamentais para construção de nossas pesquisas: a concepção de criança como sujeito com direito ao conhecimento e desenvolvimento integral; o pensamento espacial como campo interdisciplinar e fundamental para Educação Geográfica; e a sequência didática enquanto metodologia de ensino.

A pesquisa realizada tem se pautado na teoria histórico cultural (VIGOTSKI, 2009), tomando a linguagem e a fala enquanto mediadora do conhecimento e na perspectiva histórico crítica (SAVIANI, 2003) concebendo a escola como um lugar do acesso ao conhecimento acumulado historicamente pela humanidade.

Assim, a pesquisa desenvolvida tem como base a relação entre 0 Pensamento Espacial, a Geografia e os pressupostos de desenvolvimento infantil, pois estudamos a compreensão de princípios geográficos pelas crianças, a partir de problemas ou temas representativos do universo infantil, referentes ao pensamento ou relações espaciais adequadas ao momento de seu desenvolvimento, mediadas pela linguagem. A metodologia qualitativa a partir da investigação indutiva dos dados norteou todo o processo da pesquisa, desde a concepção do problema aqui tratado, a coleta e a construção de dados em campo até a análise.

O campo de pesquisa correspondeu às turmas de Educação Infantil com crianças de 4 a 6 anos de idade e os dados foram produzidos a partir de atividades de ensino, pois tomamos as interações das crianças por meio de falas e gestos, bem como suas produções como fundamentais para subsidiar nosso diálogo com a teoria. O desenvolvimento dessa pesquisa demandou uma metodologia qualitativa na construção e análise dos dados, sendo coerente com nossos objetivos e referenciais teóricos. Essa metodologia nos permite interpretar os diálogos entre as crianças, como formas de compreender quais habilidades do pensamento espacial são desenvolvidas nas atividades. Esta pesquisa consiste em um trabalho descritivo,

Estudos Geográficos, Rio Claro, 17(1): 245-255, jan./jun. $2019 \quad$ (ISSN 1678-698X) http://www.periodicos.rc.biblioteca.unesp.br/index.php/estgeo 
no qual os dados coletados são construídos com base teórica, em um diálogo permanente entre atividade empírica e teoria.

A partir dessas concepções metodológicas, apresentaremos a relação entre iniciação cartográfica e pensamento espacial e, em seguida, apresentaremos os resultados obtidos nas atividades com as crianças.

\section{INICIAÇÃO CARTOGRÁFICA E PENSAMENTO ESPACIAL}

O pensamento espacial consiste em uma forma de pensar cuja natureza trata do espaço abrangendo três elementos: conceitos espaciais, processos de raciocínio e representações espaciais (NATIONAL RESEARCH COUNCIL, 2006). Assim, a Educação Geográfica por tratar desses três elementos e tem como objetivo analisar a realidade a partir dos conhecimentos científicos sistematizados e acumulados pela humanidade pode ampliar essa modalidade de pensamento vital para o ser humano.

A as crianças desde a mais tenra idade pode desenvolver noções espaciais, por meio da iniciação cartográfica. Alguns pesquisadores utilizam o termo alfabetização tendo em vista que trata de uma linguagem caracterizada por códigos a serem aprendidos e o mapa composto por esses códigos comunicam espacialmente um fenômeno. No entanto, este termo causou um amplo debate, pois outros pesquisadores consideravam que o emprego de "alfabetização" para a aprendizagem de materiais cartográficos era inadequado, pois limitava a ideia de identificação e interpretação de códigos e a leitura de mapas pressupõe aspectos mais abrangentes na análise espacial.

Em 1999, Passini, Almeida e Martinelli publicaram o artigo "A Cartografia para Crianças: alfabetização, educação ou iniciação cartográfica”, com o objetivo de discutir o termo adequado para nomear o processo através do qual a criança adquire a linguagem cartográfica. Os três autores afirmam a abrangência do processo para além decodificação dos códigos no mapa, inclusive afirmam a relação com o processo de leitura e escrita, o que pressupõem a compreensão, não apenas do código, mas também da sintaxe.

De fato, a alfabetização cartográfica deve ser compreendida para além da habilidade de decodificar signos, pois a linguagem é algo complexo que não se limita a este tipo de processo. Esse debate decorre dos estudos desenvolvidos no campo da linguagem e o surgimento do termo letramento como o "resultado da ação de ensinar ou aprender a ler e escrever: estado ou condição que adquire um grupo social ou um indivíduo como consequência de ter-se apropriado da escrita" (SOARES, 1998, p. 18). Esses pesquisadores não concordam com a perspectiva da transmissão de código, tendo em vista a formação social e cultural da linguagem e ainda o complexo processo na sua aquisição que envolve fatores também sociais, linguísticos e psicomotores.

Se a linguagem cartográfica tem como objetivo permitir que o aluno leia e escreva sobre seu território e que conheça outros lugares e que possa transcender os códigos de um mapa, lendo de forma crítica o mundo, podemos chamar o processo de "alfabetização cartográfica", com base em Freire (1967).

O termo alfabetização, com base em Paulo Freire, nos permite concebê-la como um processo para além da decodificação dos códigos, e consiste, sim, em um processo que, por sua vez, permite o indivíduo adentrar a cultura letrada, pois:

Estudos Geográficos, Rio Claro, 17(1): 245-255, jan./jun. 2019 (ISSN 1678-698X) http://www.periodicos.rc.biblioteca.unesp.br/index.php/estgeo 
a alfabetização é mais do que o simples domínio psicológico e mecânico de técnicas de escrever e de ler. É o domínio dessas técnicas, em termos conscientes. É entender o que se lê e escrever o que se entende. É comunicar-se graficamente. É uma incorporação. Implica, não uma memorização visual e mecânica de sentenças, de palavras, de sílabas, desgarradas de um universo existencial coisas mortas ou semimortas - mas numa atitude de criação e recriação. Implica numa autoformação de que possa resultar uma postura interferente do homem sobre seu contexto. (FREIRE, 1967, p.110)

Castellar e Moraes (2011) discutem a cartografia escolar em um campo mais amplo que está relacionada com a Educação Geográfica e nos aproxima da ideia de uma cartografia enquanto metodologia para a Educação Geográfica por ser composta de um sistema de código que permite a articulação de fatos, conceitos e sistemas conceituais geográficos e, ainda, a leitura e a escrita das características do território.

O letramento geográfico é o ponto de partida para estimular o pensamento espacial do aluno, articulando a realidade com os objetos e fenômenos representados pela linguagem cartográfica. Para isto, pode-se partir de noções cartográficas como escala, proporção, legenda, visão vertical etc. - elementos que fazem parte da alfabetização cartográfica. No caso da infância, são noções elementares que perpassam todo o conhecimento geográfico, como por exemplo, a noção de vizinhança (o que está de um lado, do outro e em cima e embaixo).

Dessa forma, a apropriação de elementos cartográficos e, portanto, da representação espacial elaborada pelo aluno, permitirá a observação e análise minuciosa e abrangente de aspectos geográficos na medida em que a Cartografia possibilita 0 trabalho em diferentes escalas e localidades. A Cartografia como linguagem usada para compreender o espaço ajuda o professor a entender até mesmo o conhecimento do aluno e aspectos culturais, psicológicos e ideológicos, para assim, avançar no ensino da ciência geográfica.

Salientamos que a Cartografia é constituída por códigos, mas sua representação e compreensão geográfica ultrapassa como dissemos a simples decodificação, uma vez que o aluno pode relacionar $\mathrm{n}$ fatores em uma localidade, por meio de um mapa em diferentes escalas.

Assim, os conhecimentos espaciais dos sujeitos podem ser mobilizados de tal forma que possam abordar conhecimentos geográficos e associar aos componentes do Pensamento Espacial e às diferentes formas de representar e de pensar o espaço. Com base nessa perspectiva, compreendemos que a importância de iniciar com as crianças representações gráficas a partir de problemas, também gráficos, envolvendo questões espaciais e da ciência geográfica.

\section{A SEQUÊNCIA DIDÁTICA: REPRESENTAÇÕES ESPACIAIS NA CONSTRUÇÃO DO CONHECIMENTO GEOGRÁFICO}

O mapa das crianças introduz noções de representação do espaço, bem como a própria ideia de mapa enquanto produção social, e ao desenhar, as crianças pensam sobre o espaço, e certos conhecimentos geográficos podem ser introduzidos. A própria ideia de mapa pressupõe a projeção das três dimensões do espaço terrestre sobre o plano, o que envolve também as concepções de superfície

Estudos Geográficos, Rio Claro, 17(1): 245-255, jan./jun. 2019 (ISSN 1678-698X) http://www.periodicos.rc.biblioteca.unesp.br/index.php/estgeo 
terrestre e de planeta. Joseph Nussbaum (1989), no texto "La Tierra como cuerpo cósmico", afirma que o planeta enquanto esfera situada em um espaço ilimitado não corresponde a uma concepção óbvia às crianças, isto é aprendido e desenvolvido ao longo dos anos.

Para investigar as noções que as crianças têm em relação à ideia de planeta, Nussbaum (1989) desenvolve uma série de investigações e conclui que as crianças apresentam cinco percepções sobre a configuração do planeta: noção 1- a Terra é plana, caracterizada pela linha do céu e do chão; noção 2- a Terra é uma bola enorme composta por hemisfério, na qual vivemos dentro, e é impossível viver sobre ela; noção 3- a Terra é esférica e sólida, mas não tem a noção de acima e abaixo; noção 4- o planeta é esférico e o espaço rodeia a Terra, e passa a ter a referência para cima e para baixo; noção 5- planeta esférico rodeado pelo espaço e os objetos têm queda em direção ao centro.

Estas noções estão esquematizadas na Figura 1, ordenadas de modo que sugerem a existência de um progresso conceitual a partir da noção 1 até a noção 5 , e os três elementos essenciais do conceito de Terra se apresentam como três variáveis ou dimensões, para demonstrar que cada elemento contribui, pelo menos, de duas maneiras diferentes (por exemplo, a "forma" pode ser plana ou esférica).

Além disto, a direção acima e abaixo é absoluta e independente da Terra, desde a noção 1 até a 3, e aos poucos essa forma de pensar e as noções espaciais passam a ter relação com a própria Terra. É importante enfatizar que na noção 1, a forma do planeta é entendida como plana e, depois, passa a ser concebida como esférica, de forma inicial na noção 2. (Figura 1).

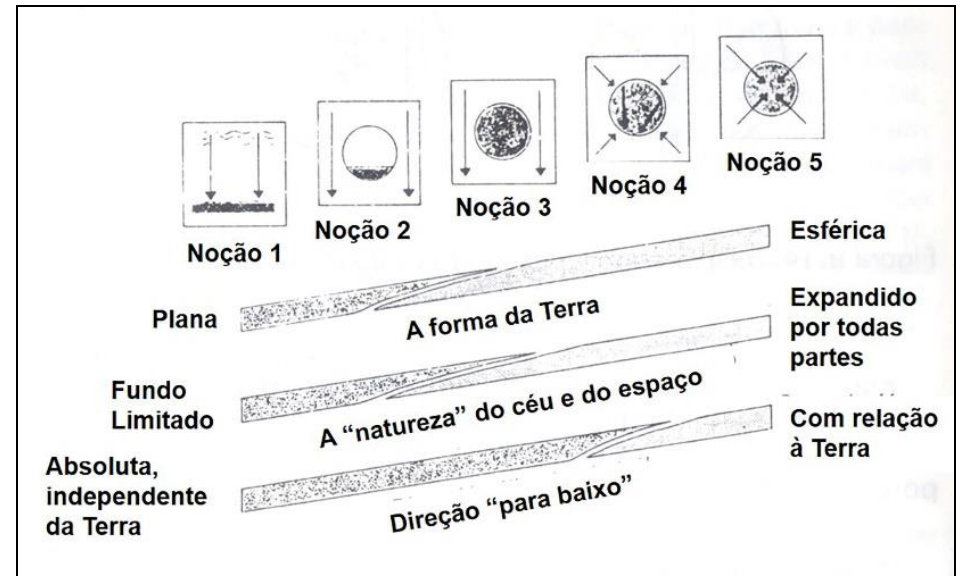

Figura 1 - Noções sobre o planeta.

Fonte: Nussbaum (1989, p. 282, tradução nossa).

A pesquisa de Nussbaum (1989) esclarece as diferentes concepções de planeta e as noções espaciais a partir de um corpo cósmico, fatores fundamentais para os estudos geográficos. Propusemos uma sequência de atividades com 0 objetivo de mobilizar o pensamento em relação à concepção de planeta, trabalhando com as noções em cima e embaixo, introduzindo a ação gravitacional por meio do uso de materiais como a esfera, além do uso de diferentes materiais que problematizassem duas visões em relação à representação do espaço, a frontal e a vertical, a partir de uma linha curva e também de um plano de base.

A pesquisa de Nussbaum (1989) contribui para conhecermos as possibilidades de representações que as crianças realizam acerca do planeta, além de problematizarmos as noções espaciais topológicas em um planeta imaginário

Estudos Geográficos, Rio Claro, 17(1): 245-255, jan./jun. 2019 (ISSN 1678-698X) http://www.periodicos.rc.biblioteca.unesp.br/index.php/estgeo 
chamado Tatipurum. Este planeta é o lugar onde se desenvolve a história infantil "A Pirilampeia e os dois meninos de Tatipurum" (SANTOS, 2000).

Nessa sequência de atividades utilizamos essa história infantil, pois problematiza a localização dos personagens em um planeta, então tomamos a localização como foco central, com o intuito de trabalhar a concepção de que os objetos estão localizados e existem condições e conexões entre eles. E neste ponto, uma narrativa infantil nos permite contar uma história com personagens que agem em um ambiente composto por tantos outros elementos, em uma sequência pressuposta pelo gênero literário.

A partir da literatura, as práticas com materiais concretos são pensadas com o objetivo de possibilitar o conhecimento prático pela criança, ou seja, saber "como" em um primeiro momento para depois o saber o "porquê", desenvolvendo 0 conhecimento conceitual. Para promover as mais variadas representações gráficas, com base em conceitos espaciais, optamos pelo uso de materiais tais como esfera, maquete, linha inclinada, linha de base e plano de base. A sequência é composta por seis atividades, direcionadas a partir das seguintes questões: 1) Onde estão os meninos?; 2) $\mathrm{O}$ que existe de diferente entre os lugares do Fulaninho e do Sicraninho?; 3) Qual foto o Fulaninho poderia tirar nessa posição?; 4) Qual foto Pirilampeia poderia tirar enquanto voa?; 5) Qual foto Pirilampeia poderia tirar do lugar onde vive Sicraninho?; 6) Como é a superfície, o chão, no qual eles pisam?

Essas questões pautaram cada uma das atividades da sequência didática. Importante ressaltar que partimos da concepção de sequência didática como forma de planejamento de aulas que deve favorecer o processo de aprendizagem por meio de atividades intencionais, desenvolvidas como situações didáticas encadeadas, compreendendo a aprendizagem como processo. Portanto, perguntamos ao longo do nosso planejamento o que ensinar, qual motivo para se ensinar, para quem ensinar e como ensinar. Esses questionamentos sempre estiveram pautados na universalidade do conhecimento e a necessidade da apropriação e transformação dos conteúdos aprendidos pelos sujeitos.

Para compreendermos de que maneira a criança vai desenvolvendo o pensamento espacial, propusemos na primeira atividade, a habilidade de influência espacial - uma vez que os personagens discutem suas posições no planeta, discutem quem está de cabeça para baixo, portanto, existe uma influência na posição que cada um ocupa. Outro fator envolvido nessa atividade é o de proximidade, pois localizam também os elementos criados pelos personagens, relacionando objetos e personagens.

$\mathrm{Na}$ segunda atividade, as crianças puderam manusear miniaturas e organizá-las em dois ambientes distintos, representados por duas maquetes, ou seja, montaram dois lugares diferentes, com o objetivo de mobilizar a habilidade de comparação espacial. A comparação espacial permite compreender os aspectos distintos e semelhantes e as relações que podem existir entre eles. Nesta atividade, propusemos às crianças um desenho individual a partir da pergunta "Se Fulaninho estiver aqui - de frente ao morro - qual fotografia ele tiraria?", a fim de analisar o ponto de vista adotado pelas crianças.

$\mathrm{Na}$ terceira atividade, apresentamos uma linha inclinada, representando a montanha da maquete, com o objetivo de entender como as crianças concebem este tipo de linha de base para suas representações espaciais. Na quarta atividade, propusemos a observação e o desenho dos lugares dos personagens a partir do ponto de vista de Pirilampeia, que sobrevoava e observava o planeta dos meninos. $\mathrm{Na}$ quinta atividade, apresentamos um plano de base com o desenho do rio visto de Estudos Geográficos, Rio Claro, 17(1): 245-255, jan./jun. 2019 (ISSN 1678-698X) http://www.periodicos.rc.biblioteca.unesp.br/index.php/estgeo 
cima e solicitamos o desenho de uma possível fotografia tirada por Pirilampeia. Para finalizar esta sequência, disponibilizamos as crianças argila e bola de isopor e propusemos a representação da superfície do planeta dos meninos.

O pensamento espacial, por meio da representação espacial, permite que o sujeito desenvolva habilidades de análise geográfica, por ter como foco o estudo da relação entre sociedade e espaço, assim, é desejável que as crianças a desenvolvam desde a Educação Infantil. Nesse sentido, a Cartografia não é de uma disciplina e sim uma linguagem, que na infância conta com diversas manifestações tendo vista as muitas linguagens expressivas, como brincadeira de faz-de-conta, materiais concretos, colagens e desenhos.

Essa linguagem contribui para o aprimoramento dos conceitos da ciência geográfica e, assim, para o desenvolvimento, além das habilidades do pensamento espacial, da alfabetização científica. A Educação Infantil pode permitir o contato inicial da criança com o conhecimento científico, de forma que possam observar, criar hipóteses, classificar, comparar, dialogar etc.

Este contato inicial favorece a Alfabetização Científica (AC), pois envolve o processo de enculturação científica - entendida como a necessidade de se compreender os múltiplos códigos e linguagem em torno de determinada cultura, no caso, a científica (CARVALHO; TINOCO, 2006) - ao passo que aborda conceitos da ciência geográfica, por exemplo, e permite aos alunos interagir com uma nova forma de ver o mundo e de analisar fenômenos espaciais. Moraes (2012) afirma que o próprio termo Alfabetização Científica tem diversas definições e opta, em suas pesquisas sobre construção de conceito, pela "concepção de Santos (2008), que atribui à alfabetização científica o uso que se faz dos conhecimentos científicos adquiridos." (MORAES, 2012, p. 223).

As propostas que dialogam com a infância e se fundamentam no desenvolvimento de princípios da ciência geográfica podem contribuir para atividades mobilizadoras do pensamento espacial, nas quais as crianças dialogam, criam hipóteses, representam suas ideias sobre um fenômeno e criam seus próprios mapas. Ou seja, a atividade criadora permite que as crianças desde cedo estejam inseridas na cultura científica e a compreendam como um constructo social.

Assim, a aprendizagem na Educação Infantil pode ser uma primeira aproximação ao conhecimento científico, a partir do "desenvolvimento da capacidade de perguntar, levantar hipóteses, buscar informações em fontes diversas, estabelecendo relações entre elas, elaborar ideias, argumentar" (GALIAN, 2012, p. 22). Compiani (2013) afirma a importância do ensino de conteúdos da geologia e da geociência para o alicerce de tantos outros conceitos que auxiliam a ler o mundo.

A Geologia/Geociências pode propiciar cognições básicas que alicercem as elaborações conceituais dos alunos, pois implicam e ampliam noções de espaço e tempo, dos condicionantes do contexto (amplos do ambiente e da sociedade, de escalas do lugar até o mundo global) para as relações de causalidades; ampliam o papel destacado da imagem e suas relações com a percepção e síntese, como, também, do argumentar e narrar histórico e de uma visão de natureza menos antropocêntrica. Cognições cujas aquisições implicam novos modos de ver, ler e explicar o mundo, novos procedimentos e novas organizações conceituais. (COMPIANI, 2013, p. 716).

Estudos Geográficos, Rio Claro, 17(1): 245-255, jan./jun. 2019 (ISSN 1678-698X) http://www.periodicos.rc.biblioteca.unesp.br/index.php/estgeo 
Assim, como na Geociência, os conceitos espaciais também são importantes e fundantes para a Geografia, pois introduzem temas e outros conceitos próprios da ciência geográfica. Queremos pontuar que nossos estudos práticos com as crianças estiveram pautados principalmente no conceito de localização para além do espaço matemático, procurando compreender também as possibilidades da Educação Geográfica e o desenvolvimento do pensamento espacial.

Para desenvolver, de fato, uma aproximação entre o conhecimento pessoal com o conhecimento científico na Educação Infantil, é necessário refletir sobre a integração entre as etapas da Educação Básica, uma vez que esta se tornou obrigatória a partir dos 4 anos de idade.

Conforme a Figura 2, podemos observar e analisar como os conceitos, as habilidades e os desenhos desenvolvem o conhecimento e representação do espaço, bem como conhecimento geográfico.

\begin{tabular}{|c|c|c|c|c|}
\hline $\begin{array}{l}\text { Sequências de } \\
\text { atividades }\end{array}$ & Conceitos & Habilidades & Desenho do espaço & $\begin{array}{l}\text { Conhecimentos da } \\
\text { representacão do espaco }\end{array}$ \\
\hline $\begin{array}{l}\text { Como é a superficie do } \\
\text { planeta Tatipurum? }\end{array}$ &  & $\begin{array}{l}\text { - Comparação espacial } \\
\text { Classificar os aspectos que se } \\
\text { assemelham e diferenciam em dois } \\
\text { espaços. } \\
\text { Palavras: mais/menos, largo/estreito, } \\
\text { maior/menor. } \\
\text { - Influência espacial } \\
\text { Identificar e criar referenciais para } \\
\text { determinar a posição de um lugar ou } \\
\text { objeto. } \\
\text { Palavras: perto/longe. } \\
\text { - Hierarquia espacial } \\
\text { Identificar que um lugar ou objeto } \\
\text { está dentro ou fora de um determinado } \\
\text { espaço; } \\
\text { Localização de elementos em um } \\
\text { plano de base. } \\
\text { Palavras: dentro/fora. }\end{array}$ & $\begin{array}{l}\text { - Visão frontal } \\
\text { Linha de base; } \\
\text { Ponto de vista } \\
\text { único. } \\
\text { - Visão vertical } \\
\text { Junção sincrética; } \\
\text { Plano de base. } \\
\text { - Profundidade } \\
\text { Transparência. } \\
\text { - Ordem de lugares } \\
\text { sem indicador } \\
\text { gráfico. } \\
\text { - Criação de } \\
\text { equivalentes. }\end{array}$ & $\begin{array}{l}\text { - Objeto no espaço } \\
\text { Investigação } \\
\text { particularidades das } \\
\text { objetos. } \\
\text { - Posição relativa no } \\
\text { espaço } \\
\text { Interioridade: uma área } \\
\text { dentro da outra; } \\
\text { Continuidade: } \\
\text { limítrofes. } \\
\text {-Referenciais espaciais } \\
\text { topológicos } \\
\text { Vizinhança, ordem, } \\
\text { separação, envolvimento. } \\
\text { - Esquema corporal e } \\
\text { projeção de referenciais em } \\
\text { cima e embaixo. } \\
\text { - Organização do espaço }\end{array}$ \\
\hline
\end{tabular}

Figura 2 - Resultados da Sequência Didática: pensamento espacial e representação do espaço.

Fonte: organização da autora.

Desenvolver as noções espaciais a partir do espaço próximo é viável, mas também podemos discuti-las a partir de questões como: "o que tem debaixo do chão?" ou "quem está de cabeça para baixo no planeta?". Pudemos verificar, na prática, as possibilidades do pensamento espacial como meio de desenvolver temas da Educação Geográfica, tendo a criança como produtora de seus mapas e de seus registros sobre um problema.

Embora as noções topológicas não sejam precisas na localização, elas são fundamentais para o desenvolvimento das habilidades do pensamento espacial, uma vez que para compreender um trajeto, a criança necessita entender a vizinhança, a separação e a ordem dos lugares, bem como para compreender a localização dos objetos em uma maquete, a criança entende o envolvimento, a ligação entre os objetos, como a relação entre ponte e rio.

Quando propusemos desenvolver a noção de planeta, também tivemos como objetivo inerente o desenvolvimento das noções de em cima e embaixo, pressupostas na existência da vida na superfície da Terra. Notamos que a palavra

Estudos Geográficos, Rio Claro, 17(1): 245-255, jan./jun. 2019 (ISSN 1678-698X) http://www.periodicos.rc.biblioteca.unesp.br/index.php/estgeo 
planeta invocou as lembranças que as crianças tinham em relação ao planeta Terra, dizendo que havia mais água do que terra ou desenhando elementos dentro de um círculo e denominando-os como "coisas que ficam em cima dos continentes".

As habilidades do pensamento espacial modificam-se ao longo do tempo ao serem mobilizadas e desafiadas e quando são mobilizadas por diferentes situações e representações os princípios como a localização são mobilizados. Na idade escolar, a Geografia e a Cartografia podem contribuir de forma significativa para o desenvolvimento deste tipo de pensamento, pois a compreensão dos princípios geográficos por meio de representações espaciais - desenhos, mapas de crianças, mapas, maquetes ou outras representações -, mobilizam as habilidades do pensamento espacial, e estas mobilizam tanto a reflexão da sua própria representação e linguagem quantos os conceitos ali representados.

\section{CONSIDERAÇÕES FINAIS}

Neste sentido, versamos sobre as condições concretas de ensino e de aprendizagem e o papel que a escola desempenha na mobilização para a leitura do mundo para assim agir e criar. Estes aspectos são fundamentais para compreender a atividade humana na construção interna do conhecimento, a aprendizagem na atividade, e sua relação com a realidade.

No estudo da Geografia, trabalhamos com diferentes modelos e representações gráficas que emitem abstrações e generalizações, do ponto de vista conceitual e refletem uma construção científica. Cabe exemplificarmos com um estudo com crianças com quatro anos de idade, na Educação Infantil. Ao desenvolvermos a noção de vida na superfície terrestre por meio de uma sequência de atividades na Educação Infantil, mobilizamos formas de pensar o espaço a partir de um modelo para o planeta, uma esfera. A partir deste material e de palavras mobilizadoras, como onde, planeta, em cima e embaixo, as crianças pensavam, conversavam e representavam a localização das pessoas e de outros seres vivos.

Estamos tratando da relação entre noções espaciais e conhecimentos geográficos, o que pode impulsionar e mobilizar uma forma de pensamento, 0 espacial. Neste caso, a mobilização ocorre principalmente por meio dos modelos e da localização, um princípio geográfico fundamental para o desenvolvimento de outros conceitos, pois permite relacionar elementos, obtendo um quadro de distribuição e distância, possibilitando a compreensão da posição de certo objeto espacial para além daquela cartesiana de intersecção de dois pontos em um plano e, assim, compreender a relação espaço-temporal, em momentos mais elevados e complexos de pensamento.

Portanto, podemos considerar que o conhecimento espacial com o enfoque geográfico pode ser elaborado pela criança desde a mais tenra idade, considerando o desenvolvimento conceitual por meio de uma rede de significados e de simples generalizações, considerando o papel da fala na aprendizagem.

\section{REFERÊNCIAS}

CARVALHO, A. M. P.; TINOCO, S. C. O ensino de Ciências como 'enculturação'. In: CATANI, D. B.; VICENTINI, P. P. Formação e autoformação: saberes e práticas nas experiências dos professores. São Paulo: Escrituras, 2006.

Estudos Geográficos, Rio Claro, 17(1): 245-255, jan./jun. 2019 (ISSN 1678-698X) http://www.periodicos.rc.biblioteca.unesp.br/index.php/estgeo 
CASTELLAR, S. M. V.; VILHENA, J. Ensino de Geografia. São Paulo: Cengage Learning, 2011.

COMPIANI, M. Narrativas e desenhos (imagens) no Ensino Fundamental com temas geocientíficos. Ciência \& Educação. Bauru, v. 19, n. 3, p. 715-737, 2013.

FREIRE, P. Educação como prática da liberdade. Rio de Janeiro: Paz e Terra, 1967.

GALIAN, C. V. A. O conhecimento de mundo na Educação Infantil como primeira aproximação do conhecimento científico. In: REIS, M.; XAVIER, M. C.; SANTOS, L. Crianças e Infâncias: educação, conhecimento, cultura e sociedade. São Paulo: Annablume, 2012, p. $19-32$.

JULIASZ, P. C. S. O pensamento espacial na Educação Infantil: uma relação entre Geografia e Cartografia. Tese (Doutorado em Educação). Faculdade de Educação. Universidade de São Paulo, 2017.

MORAES, J. V. Teoria e prática da Geografia escolar: alfabetização e enculturação científica. In: CASTELLAR, S. M. V.; CAVALCANTI, L. de S.; CALLAI, H. C. Didática da geografia: aportes teóricos e metodológicos. São Paulo: Xamã, 2012.

MOURA, M. O. et al. A atividade orientadora de ensino como unidade entre ensino e aprendizagem. In: MOURA, M. O. (org.) A atividade pedagógica na teoria histórico-cultural. Brasília: Liber Livro, 2010, p. 81-109.

NATIONAL RESEARCH COUNCIL. Learning to think spatially: GIS as a support system in the K-12 curriculum. Washington: National Research Council Press, 2006. ISBN: 0-309-53191-8, 332 p. Disponível em http://www.nap.edu/catalog/11019.html. (Acesso em 03/07/2013).

NUSSBAUM, J. La tierra como cuerpo cósmico. In: DRIVER, R; GUESNE, E. TIBERGHIEN, A. Ideas científicas em la infância y la adolescência. Traduzido por Pablo Manzano. Madrid: Ediciones Morata. 1982, p. 259 - 290.

PASSINI, E. ; ALMEIDA, R. D.; MARTINELLI, M. A cartografia para crianças: alfabetização, educação ou iniciação cartográfica. Boletim de Geografia, n. 17, p. 125 - 135, 1999.

SANTOS, J. R. A Pirilampéia e os dois menino de Tatipurum. São Paulo: Editora Ática. 2000.

SAVIANI, 2003. Pedagogia histórico-crítica: primeiras aproximações. Campinas: Autores Associados, 2003.

SOARES, M. Alfabetização no Brasil - O Estado do conhecimento. Brasília: INEP/MEC, 1987.

Estudos Geográficos, Rio Claro, 17(1): 245-255, jan./jun. $2019 \quad$ (ISSN 1678-698X) http://www.periodicos.rc.biblioteca.unesp.br/index.php/estgeo 
Pensamento espacial...

VIGOTSKI, L. S. A construção do pensamento e da linguagem. 2. ed. Tradução de Paulo Bezerra. São Paulo: Editora WMF Martins Fontes, 2009.

Estudos Geográficos, Rio Claro, 17(1): 245-255, jan./jun. 2019 (ISSN 1678-698X) http://www.periodicos.rc.biblioteca.unesp.br/index.php/estgeo 